\title{
Front Matter: Volume 11884
}

, "Front Matter: Volume 11884," Proc. SPIE 11884, International Symposium on Artificial Intelligence and Robotics 2021, 1188401 (28 October 2021); doi: 10.1117/12.2613394

SDIE Event: International Symposium on Artificial Intelligence and Robotics 2021, SPIE. 2021, Fukuoka, Japan 


\title{
PROCEEDINGS OF SPIE
}

\section{International Symposium on Artificial Intelligence and Robotics 2021}

\author{
Huimin Lu \\ Shenglin Mu \\ Shota Nakashima \\ Editors
}

\section{1-27 August 2021 \\ Fukuoka, Japan}

Organized by

International Society for Artificial Intelligence and Robotics

Sponsored by

IEEE Computer Society Big Data Technical Committee

Kyushu Institute of Technology (Japan)

Technical Cosponsor and Publisher

SPIE 
The papers in this volume were part of the technical conference cited on the cover and title page. Papers were selected and subject to review by the editors and conference program committee. Some conference presentations may not be available for publication. Additional papers and presentation recordings may be available online in the SPIE Digital Library at SPIEDigitalLibrary.org.

The papers reflect the work and thoughts of the authors and are published herein as submitted. The publisher is not responsible for the validity of the information or for any outcomes resulting from reliance thereon.

Please use the following format to cite material from these proceedings:

Author(s), "Title of Paper," in International Symposium on Artificial Intelligence and Robotics 2021 , edited by Huimin Lu, Shenglin Mu, Shota Nakashima, Proc. of SPIE 11884, Seven-digit Article CID Number (DD/MM/YYYY); (DOI URL).

ISSN: 0277-786X

ISSN: 1996-756X (electronic)

ISBN: 9781510646124

ISBN: 9781510646131 (electronic)

Published by

SPIE

P.O. Box 10, Bellingham, Washington 98227-0010 USA

Telephone +1 3606763290 (Pacific Time)

SPIE.org

Copyright (C) 2021 Society of Photo-Optical Instrumentation Engineers (SPIE).

Copying of material in this book for internal or personal use, or for the internal or personal use of specific clients, beyond the fair use provisions granted by the U.S. Copyright Law is authorized by SPIE subject to payment of fees. To obtain permission to use and share articles in this volume, visit Copyright Clearance Center at copyright.com. Other copying for republication, resale, advertising or promotion, or any form of systematic or multiple reproduction of any material in this book is prohibited except with permission in writing from the publisher.

Printed in the United States of America by Curran Associates, Inc., under license from SPIE.

Publication of record for individual papers is online in the SPIE Digital Library.

\section{SPIE. DIGITAL}

Paper Numbering: A unique citation identifier (CID) number is assigned to each article in the Proceedings of SPIE at the time of publication. Utilization of CIDs allows articles to be fully citable as soon as they are published online, and connects the same identifier to all online and print versions of the publication. SPIE uses a seven-digit CID article numbering system structured as follows:

- The first five digits correspond to the SPIE volume number.

- The last two digits indicate publication order within the volume using a Base 36 numbering system employing both numerals and letters. These two-number sets start with 00, 01, 02, 03, 04, 05, 06, 07, 08, 09, 0A, OB ... 0Z, followed by 10-1Z, 20-2Z, etc. The CID Number appears on each page of the manuscript. 


\section{Contents}

INTERNATIONAL SYMPOSIUM ON ARTIFICIAL INTELLIGENCE AND ROBOTICS 2021

1188402 Remaining useful life prediction of lithium-ion batteries based on support vector regression optimized and grey wolf optimizations [1 1884-2]

$1188403 \quad$ A prediction method for population density in key areas [1 1884-3]

$1188404 \quad$ BASNet: improving semantic segmentation via boundary-assistant symmetrical network (Invited Paper) [1 1884-4]

1188405 Simulations and experiments for the dynamic engagement characteristics of the wet clutch [1 1884-9]

1188406 A trajectory tracking method of mobile robot based on sliding mode control and disturbance observer [11884-10]

1188408 The design and realization of performance test of video apps based on Android [1 1884-16]

1188409 Review of online fault diagnosis methods for the power transmissions [1 1884-17]

11884 OA Real-time research on functional distributed computer network interconnection [1 1884-20]

$11884 \mathrm{OB} \quad$ An efficient multimodal transport transaction settlement system based on block chain [11884-21]

11884 OC Application and prospect of blockchain and smart contract technology in pharmaceutical supply chain [1 1884-22]

11884 OD Salient object detection based on Drosophila vision-inspired model [1 1884-26]

$11884 \mathrm{OE} \quad$ Bear fault diagnosis based on multiscale feature learning [1 1884-29]

11884 OF Stock price prediction via image-based DCNN with CBAM [1 1884-30]

11884 OG Innovation of heavy industry enterprise management model [11884-38]

$11884 \mathrm{OH} \quad$ A hybrid and regenerative model chat robot based on LSTM and attention model [1 1884-39]

11884 0l A novel single image reflection removal method (Invited Paper) [11884-49]

$118840 \mathrm{~J} \quad$ Image target classification detection [11884-34] 
11884 OK Underwater image super-resolution using SRCNN [1 1884-35]

$11884 \mathrm{OL} \quad$ Appearance-based gaze estimation with multi-modal convolutional neural networks [11884-36]

$118840 \mathrm{M} \quad$ Image quality improvement using local adaptive neighborhood-based dark channel prior [1 1884-40]

11884 ON Review of the intelligent fault-location in the transmission line [1 1884-41]

1188400 DoS-resisting two-factor remote authentication and key exchange scheme with user anonymity for mobile communication [11884-42]

11884 OP Shape restoration by shadow information and photometric stereo [1 1884-46]

$11884 \mathrm{OQ} \quad$ An artificial bee colony algorithm with an improved updating strategy [1 1884-47]

11884 OR Center heatmap attention for few-shot object detection [1 1884-48]

11884 OS Proposal of automatic trash system of pet sheet for driving [1 1884-51]

11884 OT A new biometric-based, mutual authenticated certificateless key agreement protocol for telecare medical information system [1 1884-52]

$11884 \mathrm{OU} \quad$ A review of natural language processing for financial technology [1 1884-54]

11884 OV Improved transfer learning based on EMD for Parkinson's diagnosis [1 1884-55]

11884 OW Research on the technology of optical motion capture system for robot inspection [11884-56]

$118840 \mathrm{X} \quad$ An adaptive anchor neural network for defect detection in aluminum profiles images [1 1884-58]

11884 OY Customer data privacy protection method based on singular value decomposition clustering algorithm [1 1884-60]

$11884 \mathrm{OZ} \quad$ A Grey Wolf optimization algorithm with its application on the controller placement problem [11884-61]

$1188410 \quad$ Retinex based underwater image enhancement using attenuation compensated color balance and gamma correction [11884-62]

$1188411 \quad$ PET-CT images co-segmentation of lung tumor using joint level set model [1 1884-63]

1188412 Multi-scale underwater object tracking by adaptive feature fusion [1 1884-64] 
1188413 The data sharing security system of cloud storage [1 1884-65]

1188414 The spatial data sharing security model based on hybrid encryption algorithm [1 1884-66]

1188415 Online-GCN: an online interactive segmentation method based on graph convolutional network [11884-67]

1188416 The correlation analysis model of information security events based on the adaptive optimization algorithm [11884-68]

$1188417 \quad$ Bayesian estimation of the inverted Beta-Liouville mixture models with extended variational inference [1 1884-69]

1188418 Visual relation of interest detection based on part detection [1 1884-70]

1188419 Multi-task infrared pedestrian detection method [11884-71]

$118841 \mathrm{~A} \quad$ Comparison of grape flower counting using patch-based instance segmentation and densitybased estimation with convolutional neural networks [1 1884-72]

11884 1B Information transmission system based on visual recognition between internal and external networks under physical isolation [1 1884-74]

11884 1C Research on stability and accuracy of the OptiTrack system based on mean error [11884-75]

11884 1D Tag generation method based on topic information [11884-76]

11884 1E RLGC: residual low rank group sparsity constraint for image denoising [1 1884-77]

11884 IF Power consumption behavior analysis based on cluster analysis [11884-78]

11884 1G Multi-agent reinforcement learning for prostate localization based on multi-scale image representation [1 1884-79]

$118841 \mathrm{H} \quad$ Object tracking based on response maps fusion Siamese network [1 1884-81]

$1188411 \quad$ Research on object tracking algorithm via adaptive multi-feature fusion [1 1884-82]

$118841 \mathrm{~J}$ Depression recognition based on text and facial expression [11884-85]

$118841 \mathrm{~K} \quad$ Research on artificial intelligence analysis technology for microscopic characteristics of shale gas reservoir (Invited Paper) [1 1884-86]

$118841 \mathrm{~L} \quad$ Using VIVE tracker to detect the trajectory of mobile robots [11884-87]

$118841 \mathrm{M} \quad$ Numerical simulation of cruise ship cabin fire based on FDS [1 1884-89] 
$118841 \mathrm{~N} \quad$ Non-convex penalty based multimodal medical image fusion via sparse tensor factorization [1 1884-88]

1188410 Temperature prediction based on LSTM-ELM network under wide and narrow band fusion [1 1884-90]

$118841 \mathrm{P} \quad$ Research on path tracking control method of unmanned surface vehicle based on deep reinforcement learning [1 1884-91]

$118841 Q \quad$ A hybrid architecture of DenseNet201 and XGBoost to detect fuberculosis from chest X-ray [1 1884-92]

$118841 \mathrm{R} \quad$ Improved threshold recognition of the coal and the gangue by using x-ray image [11884-93]

11884 is Automatic small target detection in complex background: a state of-the-art survey [1 1884-94]

$118841 \mathrm{~T} \quad$ Variational local gradient threshold driven convex optimization for single image reflection suppression [1 1884-95]

$118841 \mathrm{U} \quad$ Attention mutual teaching network for unsupervised domain adaptation person reidentification [1 1884-96]

11884 IV Pedestrian detection based on I-HOG feature [1 1884-99]

11884 IW Passive video surveillance system [1 1884-100]

$118841 \mathrm{X} \quad$ Context-aware network for pulmonary nodule detection in CT images [11884-101]

$118841 \mathrm{Y}$ A small object detection algorithm based on improved faster RCNN [1 1884-102]

1188412 Multicast beamforming planning based on massive MIMO antenna array [1 1884-103] 